\title{
Congenital Heart Disease with Arrhythmia in a Family
}

\author{
R. AMARASINGHAM* AND H. A. FLEMING \\ From the Cardiac Unit, Papworth Hospital, and Addenbrooke's Hospital, Cambridge
}

Familial occurrence of arrhythmias has been described only rarely in the past. Bacos, Eagan, and Orgain (1960) reported a family group, including three generations, with nodal bradycardia; and Wallgren and Agorio (1960) described congenital complete A-V block in three sibs, two of whom died in the neonatal period. Another group also including three generations, some members of which had congenital heart block, was reported by Gazes et al. (1965). Khorsandian, Moghadam, and Müller (1964) described a family group with A-V dissociation with occasional ventricular capture, and Wright, Adams, and Anderson (1959) investigated 12 cases with congenital A-V dissociation due either to complete or to advanced A-V block, but none of them had organic congenital heart lesions: two were sibs of a patient with congenital heart block. In their review of the reports of congenital A-V dissociation with congenital heart disease a variety of lesions was recorded, but there were only two with atrial septal defect, one of which also had partial anomalous pulmonary venous drainage. We have investigated a family group of which three members have both hæmodynamic and rhythm disturbances of the same type. The arrhythmia in particular, though a trivial feature of the heart disease, is of interest as it is an unusual one. It consists of intermittent $\mathrm{A}-\mathrm{V}$ dissociation and first-degree heart block.

The family consists of the parents and four children. Of these the mother and two children (aged 4 and 10 years) have been examined and found to be normal. One other child died of bronchopneumonia at the age of 6 months but at necropsy the heart was normal. There is no consanguinity between the parents.

This paper is concerned with the father and twin sisters aged 8 years who have congenital heart

Received March 9, 1966.

* Present Address: Cardiac Investigation Unit; General Infirmary, Leeds. disease and a degree of A-V block. The children were investigated at the age of 6 years.

\section{CASE Reports}

Case 1. J.S., the father, now aged 32 and without symptoms, was first seen at the age of 7 years with a complaint of breathlessness, and a tentative diagnosis of ventricular septal defect was made. Radiographs taken at this time are not available but a standard three limb electrocardiogram (Fig. 1) showed slight sinus arrhythmia and a conspicuously proionged P-R interval. He was advised to restrict his activities, but he ignored this and played football for his school without symptoms. He was next re-examined when the cardiac lesions were detected in his twin daughters.

The relevant features on examination were a normal appearance, a regular pulse at 70 a minute, and occasional cannon $A$ waves visible in the jugular venous pulse. There was no clinical cardiac enlargement, and on auscultation the first heart sound varied in intensity. There was wide and nearly fixed splitting of the second heart sound, and phonocardiography showed that this split varied from 0.03 to 0.06 second.

The electrocardiogram showed a prolonged P-R interval with $\mathrm{A}-\mathrm{V}$ dissociation. This dissociation was abolished by speeding the sinus pacemaker by exercise, atropine, or isoprenaline (Fig. 2). At present, when he is in sinus rhythm with $1: 1$ conduction, the P-R interval is about 0.4 second. This is slightly more prolonged than at the age of 7 when it was $0 \cdot 28$ second.

Chest radiograph showed slight cardiomegaly with prominence of the pulmonary arteries and mild pulmonary plethora.

Right heart catheterization with dye-dilution studies showed the following: (1) Left-to-right shunt at atrial or superior vena cava level; (2) no anomalous pulmonary veins were entered nor was the atrial septum crossed; (3) pulmonary to systemic flow ratio of $1.6: 1$; (4) pulmonary artery pressure of $50 / 15 \mathrm{~mm}$. $\mathrm{Hg}$ (mean $25 \mathrm{~mm}$. $\mathrm{Hg}$ ), with a pulmonary vascular resistance of approximately 2 units.

Case 2. D.S., one of a pair of identical twins and the daughter of J.S., is at present 8 years of age. Her 78 


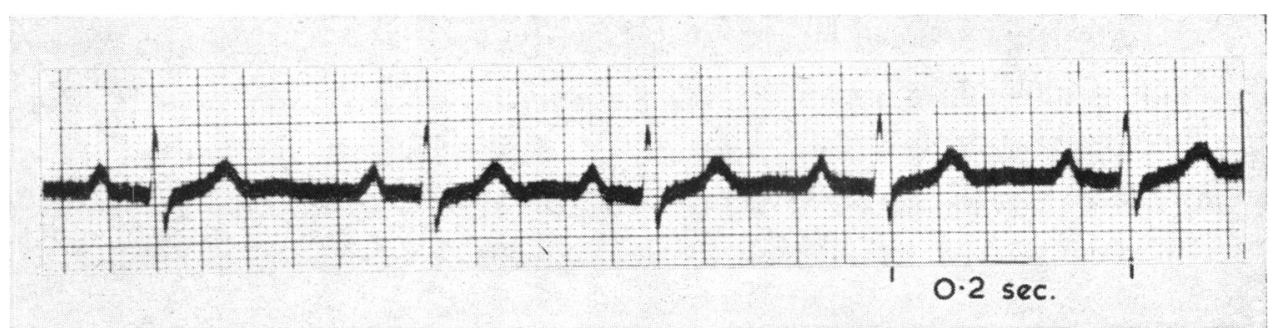

FIg. 1. Lead II from a cardiogram recorded on J.S. at the age of 7 years. It shows a slight degree of sinus arrhythmia and first-degree heart block. The $P-R$ is 0.28 sec.

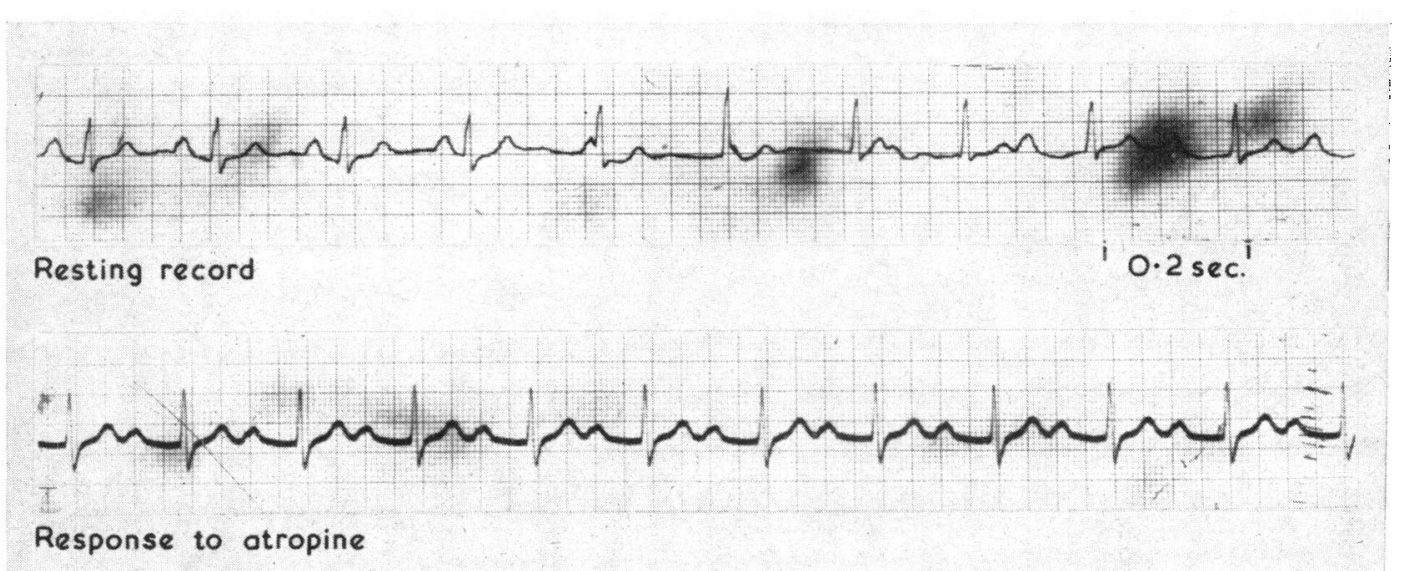

Fig. 2. This is the current cardiogram on J.S. The upper trace is a recording at rest, and it shows A-V dissociation. This is due to a nodal pacemaker discharging the ventricles, which is set at a slightly greater rate of impulse formation than the sinus pacemaker controlling the atria. The fact that this is not the result of complete heart block is shown by the lower trace. Acceleration of the sinus pacemaker by atropinization restores sinus rhythm. Now first-degree heart block is manifest, with the $P-R$ interval being approximately $0.40 \mathrm{sec}$. The responses to exercise and the administration of isoprenaline were similar.

was noted until she developed hæmaturia at the age of 5 . This has recurred and has been shown to be due to bilateral renal calculi and hydronephrosis. It was during the investigation of this condition that the heart lesions were first detected. The parents were unaware of any abnormality in this child or in her twin, but on close questioning admitted noticing some cyanosis on crying and mild exertional dyspnœa. She weighed $43 \mathrm{lb}$. (19.5 kg.) and was $3 \mathrm{ft} 11 \frac{1}{2} \mathrm{in} .(120 \mathrm{~cm}$.) in height and was slightly smaller than her twin sister. There was moderate central cyanosis and clubbing. The jugular venous pressure was not raised. The heart rate was 60 a minute and irregular. The right ventricular impulse was slightly increased and on auscultation there was a pulmonary ejection click, a moderate ejection murmur, close splitting of the second heart sound, with accentuation of the pulmonary element, and a moderate early diastolic murmur.

The electrocardiogram showed right ventricular hypertrophy. There was sinus arrhythmia with nodal rhythm during the periods of sinus slowing (Fig. 3). This gave rise to transient $\mathrm{A}-\mathrm{V}$ dissociation. This was abolished when the sino-atrial pacemaker accelerated following exercise or atropine. During normal sinus rhythm there was a delay in A-V conduction shown by a $P-R$ interval of 0.22 sec.

Chest radiograph showed moderate generalized cardiomegaly with prominence of the pulmonary arteries and slight plethora of the lung fields.

Cardiac catheterization and angiocardiography were carried out with the following findings. (1) Bi-directional shunting at atrial level; (2) atrial septal defect demonstrated but no anomalous pulmonary veins demonstrated; (3) left-sided superior vena cava draining into coronary sinus; (4) pulmonary artery pressure at systemic level and pulmonary vascular resistance of 18 units; (5) the femoral artery saturation was 91 per cent.

A diagnosis of pulmonary hypertensive atrial septal defect was made.

Case 3. V.S., the second of the identical twin daughters of J.S., weighed $3 \mathrm{lb} .12 \mathrm{oz}$. (1700 g.) at birth. No abnormality was noted either by parents or doctors until her sister's lesion had been detected at the age of 5 . 

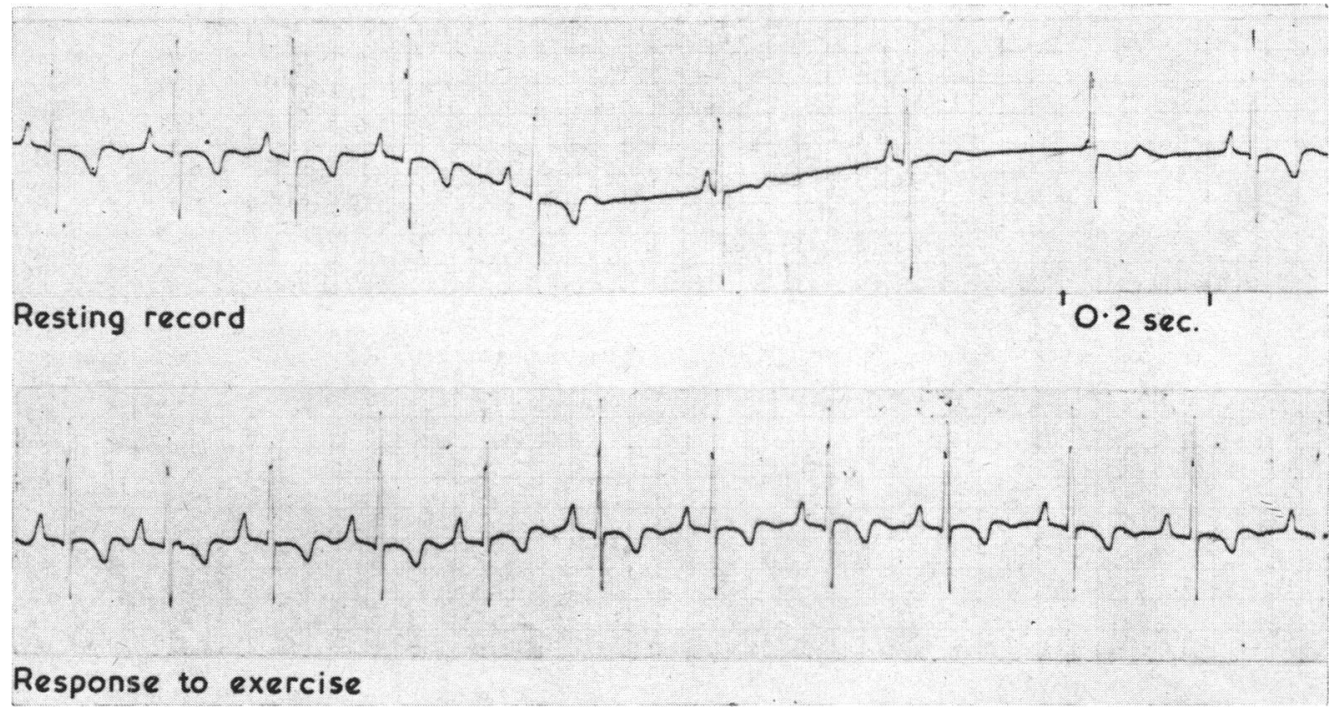

Fig. 3. Lead V1 of D.S. The resting record shows marked sinus arrhythmia. During the periods of sinus slowing a lower pacemaker discharges the ventricles, while the atria are still under the control of the sino-atrial node. This results in transient $\mathrm{A}-\mathrm{V}$ dissociation. The lower trace shows the response to exercise. With the speeding up of the sinus pacemaker, the sinus arrhythmia, and consequently the A-V dissociation, are abolished. The P-R interval is 0.22 sec. The response to atropinization was similar.

However, as with her sister, the parents did admit noting a little cyanosis on crying and some dyspnœa on exertion.

She now weighs $46 \mathrm{lb}$. (21 kg.) and is $4 \mathrm{ft} 1 \mathrm{in}$. (124 $\mathrm{cm}$.) tall. On examination the cardiovascular findings were identical to those recorded in her sister.

The electrocardiogram was very similar to that of her twin and showed right ventricular hypertrophy.
Marked sinus arrhythmia was present with nodal rhythm during the periods of sinus slowing (Fig. 4). The arrhythmia was abolished by exercise or by atropine. The $\mathbf{P}-\mathbf{R}$ interval during the conducted beats was $0 \cdot 18$ sec.

Chest radiograph showed moderate cardiomegaly with prominent pulmonary arteries and slight pulmonary plethora.
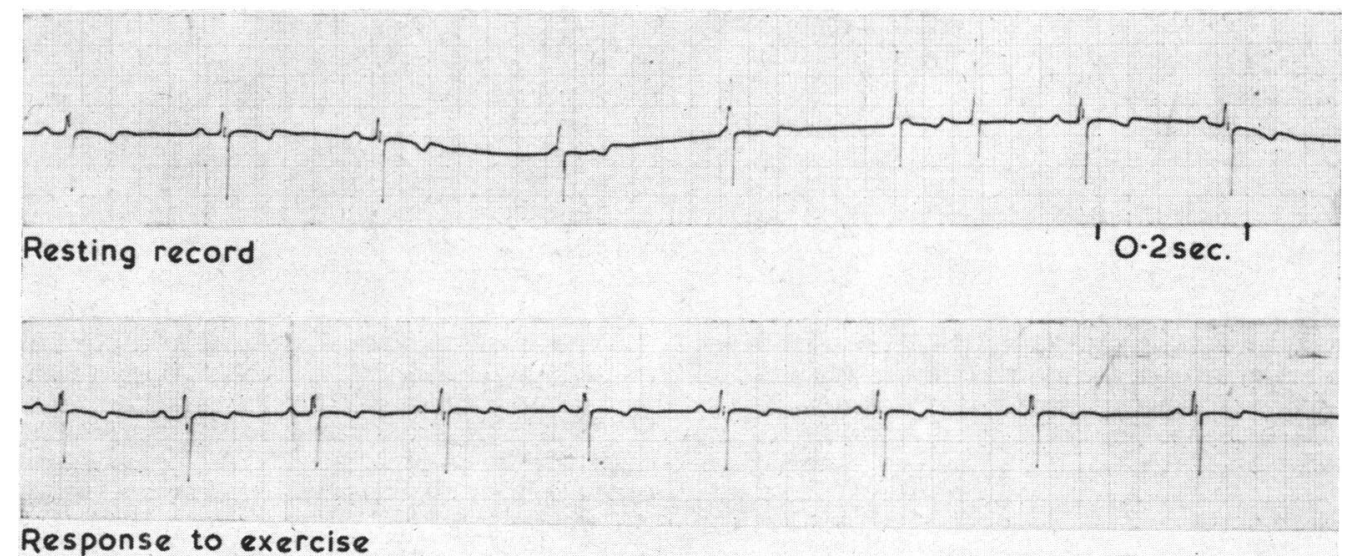

FIG. 4. Lead V1 of V.S. The record is very similar to that of D.S. (Fig. 3). The resting record shows sinus arrhythmia and transient $\mathrm{A}-\mathrm{V}$ dissociation during the periods of sinus slowing. The acceleration of the sinus pacemaker, which follows exercise, results in the abolition of the sinus arrhythmia and consequently in the $\mathrm{A}-\mathrm{V}$ dissociation. The $\mathrm{P}-\mathrm{R}$ interval is $0.18 \mathrm{sec}$. The response to atropine was similar. 
Cardiac catheterization with angiocardiography revealed the following: (1) A predominant left-to-right shunt at atrial level; (2) atrial septal defect crossed; (3) a left-sided superior vena cava was excluded and no anomalous pulmonary veins were demonstrated; (4) pulmonary artery pressure at systemic level and pulmonary vascular resistance 13 units; (5) femoral artery saturation 94 per cent.

The diagnosis again was a pulmonary hypertensive atrial septal defect but without a left-sided superior vena cava.

In this case the intravenous pyelogram was normal.

In all three cases it was notable that the rise in oxygen saturation was detected high in the superior vena cava, but all efforts to demonstrate anomalous pulmonary venous drainage failed. All three patients had cardiograms showing right axis deviation and there was no evidence of $\mathrm{A}-\mathrm{V}$ valve incompetence.

\section{Discussion}

There are two aspects to the cardiac lesions in these three cases. One is the septal defect with pulmonary hypertension, and the other the arrhythmia. Considering all the lesions there is partial concordance in this family. However, the degree of concordance between the twins is almost complete, the only point of difference being the presence of a persistent left superior vena cava in one of them. They both have central shunting at or near atrial level with pulmonary artery pressure at systemic level, the shunt at rest still appearing to be predominantly left to right.

In addition, they both show an almost identical arrhythmia with A-V conduction defect. The $P-R$ interval in one is 0.18 sec. and the other 0.22 sec. The maximum P-R interval for normal children of their age-group is $0.18 \mathrm{sec}$. for rates below 90 a minute (Alimurung and Massell, 1956). An older normal sister in this family has a P-R interval of $0.12 \mathrm{sec}$. In addition, during rest, both twins show sinus arrhythmia and a wandering pacemaker. During the periods of slowing of the sino-atrial pacemaker a lower pacemaker takes control of the ventricles with consequent atrio-ventricular dissociation: this is abolished by speeding of the sinoatrial node by exercise or atropine, so that the sinus rhythm is maintained though the A-V conduction delay persists. Each of these features is not in itself unusual. A prolonged $P-R$ interval is often found in association with congenital heart lesions, and marked sinus arrhythmia is a common feature in children. With slowing of the sinus pacemaker a lower focus may take over, controlling both atria and ventricles or only the ventricles, resulting in A-V dissociation. What is unusual is that the combination of all three with identical response to stimuli should occur in both children. This suggests that they have a similar lesion.
While the father, J.S., has an arrhythmia of similar nature, it is more bizarre. It is likely that this was of congenital origin, as the A-V conduction delay was recorded at the age of 7 years. Unlike his daughters he shows complete $\mathrm{A}-\mathrm{V}$ dissociation, with the ventricles controlled by a pacemaker (presumably in the A-V node) which is set at only a very slightly greater rate of impulse formation than the sino-atrial node which controls the atria. That this is not complete heart block is shown by the fact that speeding of the sino-atrial pacemaker by exercise or atropine restores sinus rhythm with a very long $P-R$ interval. This differs from that of his daughters only in degree. A number of separate electrocardiograms taken in childhood do not show the $\mathrm{A}-\mathrm{V}$ dissociation which is now present in all his resting electrocardiograms. It is possible that in childhood he may have had a lesser degree of $A-V$ dissociation similar to that now present in his daughters. Or, conversely, the degree of dissociation present in the twins may become more marked as they grow older.

In contrast, the hæmodynamic lesion in the father at present is much less severe than those in the children. He also has a left-to-right shunt at high atrial level but there is only a slight increase in the pulmonary artery pressure. Any discordance of his lesion compared with those of the twins appears to be one of quantity rather than quality.

It is now well established that there is a greater incidence of congenital heart disease among the families of those known to be affected. It has been estimated that the incidence of congenital heart disease in the general population is about 4 per 1000 (McKeown and Record, 1960), whereas the incidence among sibs of a propositus is about three times this figure. This greater tendency to malformation is, however, only found in the sibs of propositi. The incidence of heart disease in the parents of propositi is no greater than in the general population (Campbell, 1965). However, no figures are available for the incidence of malformation among the children of propositi.

In this report one may consider the father as the propositus as he was seen early in childhood when a diagnosis of congenital heart disease was made.

These three cases are interesting for the almost complete degree of concordance they exhibit as regards their cardiac lesion and arrhythmia. One might expect that in identical twins the degree of concordance would commonly be complete. However, twin study shows that discordance is the rule rather than the exception (Uchida and Rowe, 1957; Ross, 1959).

The arrhythmia present in these three subjects has not yet proved a problem, even in the father 
aged 32. The interest lies in the fact that it has occurred in all three subjects and it is likely that the pathogenic factors are similar and hereditary.

\section{SUMMARY}

A family is described in which the father and two identical twins among the five children have similar congenital cardiac anomalies. These consist of atrial septal defect with pulmonary hypertension and $\mathrm{A}-\mathrm{V}$ dissociation.

Our thanks are due to Dr. E. F. D. Gawne, Dr. D. Gairdner, and Dr. D. McC. Gregg for their co-operation.

\section{ADDENDUM}

Since this paper was submitted, Kahler et al. (1966) have reported two families with atrial septal defects and atrio-ventricular conduction defects. In view of the rarity of the association of conduction defects with atrial septal defects of the secundum type, they suggest that this association should always raise the possibility of the presence of a familial atrial septal defect.

\section{REFERENCES}

Alimurung, M. M., and Massell, B. F. (1956). The normal $\mathrm{P}-\mathrm{R}$ interval in infants and children. Circulation, 13, 257.
Bacos, J. M., Eagan, J. T., and Orgain, E. S. (1960). Congenital familial nodal rhythm. Circulation, 22, 887.

Campbell, M. (1965). Causes of malformations of the heart. Brit. med. F., 2, 895.

Gazes, P. C., Culler, R. M., Taber, E., and Kelly, T. E. (1965). Congenital familial cardiac conduction defects. Circulation, 32, 32.

Kahler, R. L., Braunwald, E., Plautch, W. H., and Morrow, A. G. (1966). Familial congenital heart disease. Amer. f. Med., 40, 384 .

Khorsandian, R. S., Moghadam, A., and Müller, O. F. (1964). Familial congenital A-V dissociation. Amer. F. Cardiol., 14, 118.

McKeown, T., and Record, R. G. (1960). Malformations in a population observed for five years after birth. In Ciba Foundation Symposium on Congenital Malformations, p. 2. Churchill, London.

Ross, L. J. (1959). Congenital cardiovascular anomalies in twins. Circulation, 20, 327.

Uchida, I. A., and Rowe, R. D. (1957). Discordant heart anomalies in twins. Amer. F. hum. Genet., 9, 133.

Wallgren, G., and Agorio, E. (1960). Congenital complete A-V block in three siblings. Acta paediat (Uppsala), 49, 49.

Wright, F. S., Adams, P., and Anderson, R. C. (1959). Congenital atrioventricular dissociation due to complete or advanced atrioventricular heart block. A.M.A. F. Dis. Child., 98, 72. 